\title{
MULTILETRAMENTOS E FORMAÇÃO INICIAL DE PROFESSORES DE LÍNGUA PORTUGUESA: UM OLHAR ACERCA DAS PESQUISAS NO BRASIL
}

Fernanda Maria Almeida dos SANTOS 1

\section{http://dx.doi.org/10.21165/gel.v18i2.3108}

Resumo: Na contemporaneidade, a constante utilização das tecnologias digitais tem desencadeado processos de uso da linguagem cada vez mais dinâmicos e plurais, demandando que os docentes estejam preparados para lidar com práticas de letramentos correlacionadas à diversidade semiótica dos textos e à multiplicidade cultural e linguística das sociedades. Sob essa ótica, este trabalho analisa pesquisas que discutem como os multiletramentos têm sido entendidos/promovidos nos cursos iniciais de formação de professores de Língua Portuguesa, em alguns contextos no Brasil. O referencial teórico do trabalho concilia, especialmente, os postulados de Moita Lopes (2006) e Pennycook (2006) com os pressupostos de Cope e Kalantzis (2000), Rojo (2009, 2012) e as Diretrizes da Educação Brasileira. Constata-se, por meio do mapeamento das pesquisas contidas no Banco de Teses e Dissertações da Capes (2015-2019), a necessidade de ampliação dos estudos na área, pois, de maneira geral, os trabalhos acadêmicos ainda são escassos e não desenvolvem propostas didático-metodológicas embasadas na Pedagogia dos Multiletramentos.

Palavras-chave: Multiletramentos. Tecnologias Digitais. Formação Docente. Pesquisas.

1 Universidade Federal da Bahia (UFBA), Salvador, Bahia, Brasil; fernandasantos83@hotmail.com; https://orcid.org/0000-0002-9108-0784 
- Multiletramentos e formação inicial de professores de Língua Portuguesa: um olhar acerca das pesquisas no Brasil

\title{
MULTILITERACIES AND INITIAL TRAINING OF PORTUGUESE LANGUAGE TEACHERS: A VIEW ABOUT RESEARCH IN BRAZIL
}

\begin{abstract}
Nowadays, the constant use of Digital Technologies has triggered increasingly dynamic and plural language use processes, demanding teachers to be prepared to deal with literacy practices related to the semiotic diversity of texts and the cultural and linguistic multiplicity of societies. From this perspective, this work analyzes researches that discuss how multiliteracies have been understood/promoted in the initial training courses for Portuguese language teachers in some contexts in Brazil. The theoretical framework of the work reconciles, especially, the postulates of Moita Lopes (2006) and Pennycook (2006) with the assumptions of Cope and Kalantzis (2000), Rojo (2009, 2012), and the Brazilian Education Guidelines. It is verified, through the mapping of the research contained in the Bank of Theses and Dissertations of Capes (2015-2019), the need to expand the studies in the area because, in general, academic works are still scarce and do not develop didactic proposals-methodologies based on the Pedagogy of Multiliteracies.
\end{abstract}

Keywords: Multiliteracies. Digital Technologies. Teacher Training. Research.

\section{Introdução}

A sociedade contemporânea incita e favorece o desenvolvimento de um sistema interativo, síncrono e assíncrono, de alcance global, caracterizado pela integração de diferentes linguagens. Esse modelo interacional, proveniente dos avanços tecnológicos desencadeados a partir do final do século XX, tem provocado alterações na estrutura social e, também, no desenvolvimento linguístico e cultural dos indivíduos.

Trata-se de um momento em que as formas de sociabilidade e as relações com o outro ultrapassam os limites impostos pelas noções de tempo e lugar e deslocamse, muitas vezes, do espaço físico para a dimensão midiática, propiciando a formação de ambientes virtuais de interação. Além de viabilizarem o acesso a uma incalculável quantidade de informações e oportunizarem novos modos de convivência por meio da interconectividade global, os ambientes virtuais revelam-se espaços propícios para o desenvolvimento de múltiplas aprendizagens e, portanto, para a ampliação das possibilidades de uso da linguagem. Nesse contexto, evidentemente, as discussões sobre as práticas de ensino e aprendizagem de Língua Portuguesa e, sobretudo, os processos de formação dos licenciandos em Letras não podem deixar de considerar as implicações das tecnologias digitais e dos multiletramentos na aprendizagem da língua. 
Apesar disso e do fato de os multiletramentos serem desenvolvidos em todas as fases da vida humana, as discussões sobre o tema são muito mais enfatizadas nos cursos de Pedagogia do que na Licenciatura em Letras. Os currículos dos Cursos de Licenciatura em Letras, na maioria das vezes, ainda são bastante engessados (GATTI, 2010). Há uma grande preocupação com o ensino teórico de Linguística/Língua Portuguesa (o que também é de suma importância), mas - muitas vezes - as disciplinas práticas e/ou de caráter pedagógico não conseguem inter-relacionar três elementos essenciais para a formação/ profissionalização dos graduandos: teorias linguísticas, práticas de ensino e realidade socioeducacional. Evidentemente, o trabalho disciplinar, realizado isoladamente em sala de aula, não contempla essa necessidade. Ademais, no contexto contemporâneo, é necessário que os futuros docentes sejam preparados para lidar com múltiplas práticas de leitura e escrita, o que engloba não apenas o trabalho com gêneros escritos convencionais, mas também a valorização de diferentes contextos de produção, dentre eles o digital, e de textos diversificados, quer em seus aspectos multissemióticos e/ou multiculturais.

Sendo assim, o debate contemporâneo sobre formação inicial de professores se amplia na medida em que abre espaço para o desenvolvimento de pesquisas acadêmicas que possam refletir se/como os cursos de Licenciatura em Letras têm garantido a profissionalização dos licenciandos por meio de práticas que os habilitem para o desenvolvimento dos multiletramentos na educação básica, valendo-se das tecnologias digitais. Mediante a esse cenário, emergem questionamentos como: de que maneira as pesquisas acadêmicas realizadas no Brasil têm discutido o tema Multiletramentos $e$ Tecnologias Digitais nos cursos iniciais de formação de professores de Língua Portuguesa? Que perspectivas teórico-metodológicas fundamentam as pesquisas sobre multiletramentos, desenvolvidas pelos professores-formadores no âmbito acadêmico? De que modo os multiletramentos são desenvolvidos na academia com vistas a contribuir para a ampliação das práticas de leitura e escrita na educação básica?

No intuito de refletir acerca dessas questões, sem esgotar as possibilidades de análise acerca do tema, o presente trabalho discorre/reflete sobre um mapeamento das pesquisas presentes no Banco de Teses e Dissertações da Coordenação de Aperfeiçoamento de Pessoal de Nível Superior (Capes), no período de 2015 a 2019, com o objetivo de lançar luz sobre alguns dos modos como os multiletramentos têm sido entendidos/promovidos nos cursos iniciais de formação de professores de Língua Portuguesa no Brasil.

Espera-se, portanto, por meio deste trabalho, alcançar o objetivo de fomentar as discussões teóricas no campo da Linguística Aplicada e, ao mesmo tempo, contribuir com pesquisadores e professores que atuam na educação superior, com reflexões sobre os multiletramentos e uso das tecnologias digitais e no processo de formação docente. 
- Multiletramentos e formação inicial de professores de Língua Portuguesa: um olhar acerca das pesquisas no Brasil

\section{Linguística Aplicada e Pedagogia dos Multiletramentos: intersecções e desafios para a aprendizagem de Língua Portuguesa}

$\mathrm{Na}$ contemporaneidade, refletir sobre as práticas de uso social da língua e, consequentemente, sobre os multiletramentos, dentro e fora do contexto escolar, implica refletir também sobre o papel da Linguística Aplicada (doravante LA) no ensino de línguas.

Historicamente, o desenvolvimento da LA esteve estreitamente ligado à evolução do ensino de línguas nos Estados Unidos durante e após a Segunda Guerra Mundial. Somente na segunda metade dos anos 80 é que ela foi reconhecida como uma área de investigação independente da Linguística, exercendo um movimento intradisciplinar no que diz respeito à confluência com as várias ciências-fonte para a solução de um problema de uso de linguagem. E, na década de 90, a natureza complexa e multinivelar de cada questão tomada como foco de pesquisa aplicada teorizou-se e conferiu à LA o status de ciência interdisciplinar (e, às vezes, transdisciplinar), com metodologia e objetos de estudo próprios. Passou a ter como foco as questões da linguagem inseridas na prática social real, distribuídas em várias subáreas: ensino-aprendizagem de línguas, tradução e interpretação, terminologia e lexicografia, relações sociais/profissionais mediadas pela linguagem.

É importante considerar também as mudanças sofridas pela LA no que concerne ao modo de compreender a linguagem, mediante a transformação do mundo moderno para o pós-moderno. Num contexto moderno, as relações sociais eram voltadas para o domínio social, político e econômico baseado na indústria e no trabalho produtivo. Também o racionalismo, o positivismo e os ideais de igualdade, liberdade e fraternidade tinham amplo valor. Nesse sentido, o tipo de LA associado ao modernismo tratava a linguagem como um sistema e operava segundo um paradigma de pesquisa positivista e prescritiva, que se esforçava para evitar as macroestruturas da dominação linguística e cultural. Já na sociedade pós-moderna, o domínio social, político e econômico volta-se para o capital financeiro e serviço das redes eletrônicas de automação e informação. A filosofia pósmoderna celebra a diferença e desafia as hegemonias, por meio da desconstrução dos discursos dominantes (KUMARAVADIVELU, 2006). Assim, o papel do linguista aplicado tem de se mover para além do tratamento da linguagem como um sistema e começar a tratá-la como discurso².

2 Vale ressaltar que o discurso é, nesse contexto, entendido como campo ou domínio dentro do qual a linguagem é produzida de modos particulares nas e por meio das práticas sociais, instituições e ações. (KUMARAVADIVELU, 2006). 
Desse modo, na pós-modernidade, surge uma vertente menos ortodoxa a qual defende que a LA não deve ser mais entendida como uma simples instância mediadora entre os estudos da linguagem feitos à margem dos anseios populares e uma sociedade que clama por soluções práticas, mas como interventora da explicação linguística a outras perspectivas parciais sobre a língua, de forma a propor reformulações relevantes para os problemas do mundo contemporâneo (MOITA LOPES, 2006).

Segundo Moita Lopes (2006), a problemática que se apresenta como desafio para a contemporaneidade é a de se produzir conhecimentos e, ao mesmo tempo, contemplar as vozes dos que estão à margem da sociedade, as denominadas "vozes do Sul". Assim, parte de uma perspectiva anti-hegemônica que se opõe à LA tradicional - "uma LA presa à discussão da diferença entre LA e aplicação de lingüística, não se descolando da lingüística e de seus ideais de ciência moderna" (MOITA LOPES, 2006, p. 87). Conforme o estudioso, o novo mundo de fluídas identidades globais requer processos de construção do conhecimento que devem gerar mudanças sociais. Então, propõe um processo de recriação da vida social, que está diretamente relacionado à necessidade de compreendêla. Também, de acordo com Moita Lopes (2006), a LA contemporânea deve ser entendida como uma área híbrida, ou da Indisciplina, que tem a ética e o poder como novos pilares.

Pennycook (2006) concorda em muitos aspectos com Moita Lopes. No entanto, defende uma Linguística Aplicada Crítica (LAC) à qual opõe a LA hipócrita ou tradicional. Segundo Pennycook (2006, p. 67), a LAC é

[...] uma abordagem mutável e dinâmica para as questões da linguagem em contextos múltiplos [...] Em vez de ver a LAC como uma nova forma de conhecimento interdisciplinar, prefiro compreendê-la como uma forma de antidisciplina ou conhecimento transgressivo, como um modo de pensar e fazer sempre problematizador. Isso quer dizer não somente híbrido de pesquisa e práxis, mas que gera algo que é muito mais dinâmico.

Nesse sentido, o termo "transgressão" é utilizado para marcar a intenção de romper, tanto política quanto teoricamente, os limites do pensamento e ação tradicionais. Difere-se da oposição, da reversão e, ainda, da subversão, por questionar os limites que separam as categorias e, implicitamente, interrogar os mecanismos de poder nos quais se baseiam a lei (PENNYCOOK, 2006). Na verdade, a LAC ou LA transgressiva considera as implicações da virada linguística nas ciências sociais, da virada somática (em direção ao corpo) e da virada performativa (na direção da identidade). Portanto, ela completa a visão da LA contemporânea proposta por Moita Lopes e reitera a ideia de que: 
- Multiletramentos e formação inicial de professores de Língua Portuguesa: um olhar acerca das pesquisas no Brasil

Em uma LA que quer falar à vida contemporânea é essencial, não a teorização elegantemente abstrata que ignora a prática, mas uma teorização em que teoria e prática sejam conjuntamente consideradas em uma formulação do conhecimento na qual a teorização pode ser muito mais um trabalho de bricolage, tendo em vista a multiplicidade dos contextos sociais e daqueles que os vivem. (MOITA LOPES, 2006, p. 101).

Sendo assim, Pennycook (2006) enfatiza a necessidade de se pensar: i) na interrelação entre o local e global (translocalização); ii) nos processos de interação cultural que permitem uma fluidez de relações (transculturalização); iii) no uso da linguagem com base na multiplicidade semiótica (transmodalidade); iv) no uso dos signos atravessando diferentes contextos (transtextualidade) e v) no significado como ato de interpretação que leva em conta distintos modos de compreender (tradução).

Ademais, é preciso considerar o papel do discurso na constituição do sujeito, um sujeito notadamente caracterizado por sua sócio-história e por sua natureza fragmentada, heterogênea, contraditória e fluida (HALL, 2002). Por isso, no contexto contemporâneo, o ensino de Português como Língua Materna (PLM) não pode ignorar o fato de que professores e alunos têm posicionamentos discursivos que contemplam seus corpos e suas identidades sociais. Nessa perspectiva, o processo de ensino e aprendizagem de Língua Portuguesa, de modo geral, precisa estar intrinsecamente interligado a outras áreas de conhecimento, tais como, a Antropologia, a Sociologia, a Educação, as Pedagogias Críticas, a Etnografia, os Estudos da Cultura e a Filosofia. E mais: deve ser um ensino híbrido, questionador, provocador e inter-relacionado às transformações sociais, econômicas, culturais e tecnológicas que emergem na pós-modernidade.

No que concerne especificamente ao ensino e aprendizado da leitura e da escrita, é crucial que a escola - muito mais do que a aprendizagem de elementos técnicos da língua - vise ao desenvolvimento de práticas relacionadas à dinamicidade dos textos e discursos que circulam na sociedade contemporânea, englobando os multiletramentos. A noção de multiletramentos está associada, por um lado, à multiplicidade cultural e linguística das sociedades pós-modernas e, por outro, à multiplicidade e integração de variados modos de constituição do significado, por meio da utilização de diferentes semioses (cf. NLG, 1996).

Para dar conta da multiplicidade cultural que se inter-relaciona e da pluralidade de textos que circulam nas sociedades contemporâneas, a Pedagogia dos Multiletramentos também considera a associação entre a crescente variedade de formas de textos e as Tecnologias da Informação e Comunicação. 
Até que ponto essas novas tecnologias afetam a linguagem entre as pessoas é mais um aspecto a considerar no estudo da comunicação. Se por um lado é a mesma pessoa que fala, favorecendo uma abordagem unificadora e, a meu ver, mais fácil de ser tratada porque incorpora o que já conhecemos - por outro lado, as novas tecnologias introduzem mudanças que afetam a comunicação e nos obrigam a reconsiderar o que já parecia estar estabelecido. Pesquisar um fenômeno que ocorre sempre da mesma maneira, dentro dos mesmos padrões de regularidade, já é um desafio para o pesquisador. Estudar um fenômeno que muda entre o início e o fim da própria pesquisa é um desafio bem maior; quando termina o estudo o objeto inicial já se transformou em algo diferente. A mobilidade desse objeto exige, portanto, um paradigma de pesquisa altamente adaptável, que seja capaz de incorporar essas mudanças no momento em que elas ocorrem, uma espécie de "just in time" metodológico. Daí, o grande desafio da pesquisa em Linguística Aplicada. (LEFFA, 2001, p. 3-4).

E, partindo do princípio de que a Linguística Aplicada tem como desafio analisar questões de uso da linguagem na prática, seja dentro ou fora do contexto escolar, considerando as mudanças impulsionadas pelas diferentes tecnologias, bem como pelas mais variadas sociedades, culturas, tipos e modos diferenciados de linguagem, é possível afirmar também que outro desafio que se coloca para a LA no contexto contemporâneo é compreender como a formação inicial de professores tem sido desenvolvida, no âmbito do processos de aprendizagem da leitura e da escrita, de modo a contemplar a multiplicidade cultural, linguística e semiótica impulsionada por meio das tecnologias digitais. No intuito de refletir sobre tal temática, a seção a seguir enfatizará a importância dos multiletramentos e do uso das tecnologias digitais no processo de formação dos licenciandos em Letras.

\section{Multiletramentos, tecnologias digitais e formação inicial de professores de Língua Portuguesa}

Historicamente, as práticas de uso da escrita na esfera escolar sustentaram-se num modelo autônomo, parcial e inadequado de letramento, o qual considera a aquisição da escrita um processo neutro, que independe de aspectos sociais e contextuais e centra-se no desenvolvimento de atividades mecânicas de leitura e de produção de gêneros de textos abstratos ${ }^{3}$, promovendo uma separação polarizada entre oralidade e escrita (STREET,

3 A ideia de abstração, segundo Street (1993), refere-se aqui tanto ao distanciamento do interlocutor do contexto imediato de produção do texto, quanto à valorização do emprego de elementos linguísticos formais e à própria maneira de desenvolvimento temático do texto. 
- Multiletramentos e formação inicial de professores de Língua Portuguesa: um olhar acerca das pesquisas no Brasil

1993). Esse é, sem dúvida, um modelo de letramento limitado, visto que se centra, apenas, no ensino formal da escrita; não considera os diversos contextos de produção, nem leva em conta como são construídas as relações de poder, identidade e valores sobre a cultura escrita na esfera escolar. Como explicita Silva (2006, p. 77),

[...] o conhecimento trabalhado dentro dessa concepção, que não considera a prática social, veicula, de modo consciente ou não, as ideologias da sociedade dominante. E como não trabalha para que as pessoas envolvidas tenham consciência crítica, essas ideologias não são contestadas. Com isso, as pessoas, geralmente, não percebem as manipulações a que estão se assujeitando. $\mathrm{O}$ modelo autônomo parte da visão de que o conhecimento é algo para ser apenas consumido e não produzido, transformado, desafiado.

Em virtude das limitações desse modelo, uma perspectiva diferente acerca das relações entre letramento e sociedade é proposta por aqueles que se filiam a uma vertente antes denominada de uma interpretação radical, ou "revolucionária", dessas relações. Street (1993), um dos representantes dessa vertente, caracteriza-a como o "modelo ideológico" de letramento. Nas palavras do autor:

Em oposição, então, ao estudo do letramento como uma das ferramentas cognitivas de um indivíduo ou como uma função neutra das instituições, a conceitualização do letramento como prática ideológica abre um campo potencialmente rico de investigação sobre a natureza da cultura e poder, e a relação entre instituições e ideologias de comunicação no mundo contemporâneo. (STREET, 1993, p. 11-12, tradução nossa4).

Admite-se, assim, que as formas as quais as práticas de leitura e escrita assumem em efetivos contextos sociais são ideologicamente determinadas e dependem fundamentalmente das instituições sociais que propõem e exigem essas práticas. Nesse sentido, o letramento escolar é entendido não numa perspectiva curricular centrada em aspectos metodológicos e/ou conteudísticos, mas numa abordagem social e etnográfica (epistemológica e metodologicamente voltada para a percepção das diferenças entre os grupos humanos, culturas e sociedades), que favoreça a dinâmica da construção do conhecimento, por meio da efetiva inserção dos educandos em diversificadas práticas de

4 No original: "In contrast, then, to the study of literacy as either an individual cognitive tool or as a neutral function of institutions, the conceptualization of literacy as ideological practice opens up a potentially rich field of inquiry into to nature of culture and power, and the relationship of institutions and ideologies of communication in the contemporary world". 
uso dos múltiplos gêneros textuais. Não há mais espaço para o enaltecimento de práticas homogeneizadoras, centralizadas na produção de textos de gêneros convencionais, que visam a supremacia de um grupo sobre os demais. Emerge, no contexto atual, a necessidade da valorização/desenvolvimento de práticas de letramentos múltiplos que englobem os diferentes sujeitos, considerando suas especificidades.

Os letramentos múltiplos referem-se, segundo Rojo (2012, p. 53-54), às mais variadas práticas de leitura e escrita existentes na sociedade, sejam elas escolares ou não escolares, "locais ou globais, valorizadas ou não valorizadas". Englobam, portanto, o letramento escolar e o acadêmico, os letramentos multissemióticos, os letramentos críticos e protagonistas e, também, os multiletramentos.

De acordo com Rojo (2012, p. 12),

Diferentemente do conceito de letramentos (múltiplos), que não faz senão apontar para a multiplicidade e variedade das práticas letradas, valorizadas ou não nas sociedades em geral, o conceito de multiletramentos - é bom enfatizar - aponta para dois tipos específicos e importantes de multiplicidade presentes em nossas sociedades, principalmente urbanas, na contemporaneidade: a multiplicidade cultural das populações e a multiplicidade semiótica de constituição dos textos por meio dos quais ela se informa e se comunica.

Historicamente, o termo multiletramentos deriva do vocábulo inglês multiliteracies, cunhado, em 1994, pelo New London Group (Grupo de Nova Londres) - equipe de estudiosos de áreas de especialização distintas que se dedicou a uma importante discussão acerca dos estudos de letramento e das novas demandas educacionais face à globalização, à tecnologia e à diversidade social/cultural. Cope e Kalantzis - precursores, dentre outros, desse grupo - associam a criação do termo a dois fatores importantes e estreitamente correlacionados:

Primeiro, nós queremos estender a ideia e campo da pedagogia do letramento para explicar o contexto da nossa diversidade cultural e linguística e das sociedades cada vez mais globalizadas, para dar conta da cultura multifacetada que se inter-relaciona e da pluralidade de textos que circulam. Segundo, nós defendemos que a pedagogia do letramento agora deve levar em conta a variedade crescente de formas de textos associados com tecnologias de informação e multimídia. Isso inclui a compreensão e controle competente de formas de representação que estão se tornando cada vez mais significativas nos ambientes globais de comunicação, tais como imagens visuais e sua relação 
- Multiletramentos e formação inicial de professores de Língua Portuguesa: um olhar acerca das pesquisas no Brasil

com a palavra escrita - por exemplo a imagem visual em editoração eletrônica ou a interface entre o significado visual e linguístico em multimídia. (COPE; KALANTZIS, 2000, p. 9, tradução nossa ${ }^{5}$ ).

Nota-se assim que, além da multiculturalidade característica das sociedades globalizadas e da multimodalidade dos textos que circulam nessas sociedades, uma das ideias-chave acerca da noção de multiletramentos, conforme os autores, é a crescente complexidade e inter-relação dos diferentes modos de significado: linguístico, visual, áudio, gestual, espacial e multimodal, sendo que "dos modos de significação, o multimodal é o mais importante, pois relaciona todos os outros modos em relações notavelmente dinâmicas" (COPE; KALANTZIS, 2000, p. 28, tradução nossa6 ${ }^{6}$.

Mas é importante ressaltar que

Trabalhar com multiletramentos pode ou não envolver (normalmente envolverá) o uso de novas tecnologias de comunicação e de informação ("novos letramentos"), mas caracteriza-se como um trabalho que parte das culturas de referência do alunado (popular, local, de massa) e de gêneros, mídias e linguagens por eles conhecidos, para buscar um enfoque crítico, pluralista, ético e democrático - que envolva agência - de textos/discursos que ampliem o repertório cultural, na direção de outros letramentos [...]. (ROJO, 2012, p. 8).

Contudo, não se pode deixar de reconhecer que, na contemporaneidade, o desenvolvimento e o uso crescente das tecnologias digitais e das redes de comunicação interativa acompanham e amplificam uma profunda mutação nas relações com o saber, possibilitando, assim, novas formas de aprendizagem da leitura e da escrita. Apesar disso, nos currículos dos cursos de Licenciatura, segundo Gatti (2010), ainda prevalece a tradição disciplinar. Por meio de uma análise dos currículos de 32 (trinta e dois) cursos de Licenciatura em Letras de diferentes universidades localizadas nas cinco regiões brasileiras, Gatti (2010) observa, entre outros aspectos, que: i) os cursos de Licenciatura

5 No original: "First, we want to extend the idea and scope of literacy pedagogy to account for the context of our culturally and linguistically diverse and increasingly globalized societies, for the multifarious cultures that interrelate and the plurality of texts that circulate. Second, we argue that literacy pedagogy now must account for the burgeoning variety of text forms associated with information and multimedia technologies. This includes understanding and competent control of representational forms that are becoming increasingly significant in the overall communications environment, such as visual images and their relationship to the written word - for instance, visual design in desktop publishing or the interface of visual and linguistic meaning in multimedia.".

6 No original: "Of the modes of meaning, the Multimodal is the most significant, as it relates all the other modes in quite remarkably dynamic relationships.". 
em Letras destinam a maior parte de sua carga horária $(51,4 \%)$ a disciplinas relativas aos conhecimentos disciplinares da área, com predominância da Linguística; ii) boa parte dos ementários analisados não demonstra uma articulação entre as disciplinas de formação específica (conteúdos da área disciplinar) e a formação pedagógica (conteúdos para a docência) e iii) saberes relacionados ao uso das tecnologias estão praticamente ausentes. Lima e Loureiro (2016, p. 146) ainda acrescentam outros fatores que atestam falhas significativas no processo de formação dos licenciandos: "[...] [2] as formações não enfatizam a importância da fundamentação epistemológica das ações didáticas e metodológicas; e [3] o uso das tecnologias digitais não produz novas metodologias e didáticas".

Nesses moldes, os cursos de Licenciatura em Letras, além de privilegiarem uma especificação do saber (ora na área da Linguística, ora no campo da Literatura), desenvolvem, muitas vezes, uma formação desvinculada da realidade socioeducacional e da diversidade cultural presente em nossa sociedade, bem como das práticas multimodais e multiculturais que permeiam um século marcado pelo avanço das tecnologias digitais. Distancia-se, desse modo, das diretrizes legais que norteiam a formação docente, como detalhamos a seguir.

É importante salientar que, desde o final da década de 1990, a legislação federal que orienta os currículos dos cursos de licenciatura em letras já preconiza o uso das tecnologias mais contemporâneas no processo de formação de professores, bem como o desenvolvimento de práticas educativas que valorizem as diferentes linguagens. $\mathrm{O}$ Decreto $n^{0}$ 3.276, de 1999, que dispõe sobre a formação em nível superior de professores para atuar na educação básica, e dá outras providências, estabelece - em seu Artigo 50 parágrafo $1^{\circ}$ - que uma das competências a serem desenvolvidas pelos professores que atuarão na educação básica diz respeito ao domínio do conhecimento pedagógico, incluindo as novas linguagens e tecnologias, considerando os âmbitos do ensino e da gestão, de forma a promover a efetiva aprendizagem dos alunos (BRASIL, 1999).

Também as Diretrizes Curriculares Nacionais para a Formação de Professores da Educação Básica, em nível superior, curso de licenciatura, de graduação plena, de 2002, em seu artigo $2^{\circ}$, recomendam:

A organização curricular de cada instituição observará [...] outras formas de orientação inerentes à formação para a atividade docente, entre as quais o preparo para: [...] VI - o uso de tecnologias da informação e da comunicação e de metodologias, estratégias e materiais de apoio inovadores. (BRASIL, 2002, p. 1, grifo nosso). 
- Multiletramentos e formação inicial de professores de Língua Portuguesa: um olhar acerca das pesquisas no Brasil

Em 2015, o referido documento é atualizado, em virtude da necessidade de se articular as Diretrizes Curriculares Nacionais para a Formação Inicial e Continuada, em Nível Superior, e as Diretrizes Curriculares Nacionais para a Educação Básica (2013). Em seu Artigo $3^{\circ}$, parágrafo $5^{\circ}$, fica evidente que um dos princípios da Formação de Profissionais do Magistério da Educação Básica é:

II - a formação dos profissionais do magistério (formadores e estudantes) como compromisso com projeto social, político e ético que contribua para a consolidação de uma nação soberana, democrática, justa, inclusiva e que promova a emancipação dos indivíduos e grupos sociais, atenta ao reconhecimento e à valorização da diversidade e, portanto, contrária a toda forma de discriminação. (BRASIL, 2015, p. 4).

O Artigo $5^{\circ}$ também recomenda que a formação de profissionais do magistério conduza o(a) egresso(a):

I - à integração e interdisciplinaridade curricular, dando significado e relevância aos conhecimentos e vivência da realidade social e cultural, consoantes às exigências da educação básica;

\section{$[\ldots]$}

V - à elaboração de processos de formação do docente em consonância com as mudanças educacionais e sociais, acompanhando as transformações gnosiológicas e epistemológicas do conhecimento;

VI - ao uso competente das Tecnologias de Informação e Comunicação (TIC) para o aprimoramento da prática pedagógica e a ampliação da formação cultural dos(das) professores(as) e estudantes;

VII - à promoção de espaços para a reflexão crítica sobre as diferentes linguagens e seus processos de construção, disseminação e uso, incorporandoos ao processo pedagógico, com a intenção de possibilitar o desenvolvimento da criticidade e da criatividade. (BRASIL, 2015, p. 6).

Nesse contexto, a docência é concebida como uma ação educativa que envolve conhecimentos específicos, interdisciplinares e pedagógicos, voltados para a construção devalores éticos, linguísticos, estéticos, políticos, sociais e culturais, e em diálogo constante com as transformações da sociedade contemporânea e com as diferentes visões de mundo. Sendo assim, consoante os documentos nacionais que orientam os cursos de Licenciatura, 
de modo geral, e a Licenciatura em Letras, de modo mais específico, a formação inicial do professor de Língua Portuguesa deve valorizar o estudo de práticas linguísticas interativas e interpretativas, que envolvam diferentes propósitos comunicativos, bem como valores étnicos, raciais, culturais, religiosos, de gênero/orientação sexual e outros, por meio do recursos semióticos e tecnológicos variados, englobando - assim - os multiletramentos.

\section{Um olharsobre as pesquisas e práticas de ensino que envolvem multiletramentos e tecnologias digitais na formação inicial de professores de Língua Portuguesa}

Com o objetivo de analisar estudos que discutem como os multiletramentos têm sido entendidos/promovidos nos cursos iniciais de formação de professores de Língua Portuguesa no Brasil, realizou-se um mapeamento das pesquisas presentes no Banco de Teses e Dissertações on-line da Capes. A busca dos trabalhos se deu a partir do termo multiletramentos e o escopo da investigação foram as Teses e Dissertações publicadas no Brasil, no período de 2015 a 2019. Por meio da referida pesquisa, foram encontrados 422 trabalhos, conforme apresenta o Quadro 1.

Quadro 1. Distribuição das pesquisas sobre multiletramentos no período de 2015 a 2019

\begin{tabular}{|c|c|c|c|c|}
\hline $\begin{array}{c}\text { ANO DE } \\
\text { PUBLICAÇÃO }\end{array}$ & $\begin{array}{c}\text { DISSERTAÇÃO } \\
\text { (MESTRADO } \\
\text { PROFISSIONAL) }\end{array}$ & $\begin{array}{c}\text { DISSERTAÇÃO } \\
\text { (MESTRADO } \\
\text { ACADÊMICO) }\end{array}$ & $\begin{array}{c}\text { TESE } \\
\text { (DOUTORADO) }\end{array}$ & $\begin{array}{c}\text { QUANTIDADE } \\
\text { DE } \\
\text { PUBLICAÇÕES }\end{array}$ \\
\hline $\mathbf{2 0 1 5}$ & 39 & 44 & 7 & 90 \\
\hline $\mathbf{2 0 1 6}$ & 36 & 36 & 10 & 82 \\
\hline $\mathbf{2 0 1 7}$ & 22 & 39 & 16 & 77 \\
\hline $\mathbf{2 0 1 8}$ & 55 & 35 & 8 & 98 \\
\hline $\mathbf{2 0 1 9}$ & 31 & 34 & 10 & 75 \\
\hline TOTAL & $\mathbf{1 8 3}$ & 188 & 51 & 422 \\
\hline
\end{tabular}

Fonte: Elaboração própria

No intuito de realizar uma seleção das publicações que tratavam especificamente dos multiletramentos e tecnologias digitais na formação inicial de professores de Língua Portuguesa, efetuou-se uma análise do título e do resumo de cada uma das 422 publicações, bem como verificou-se se elas apresentavam como uma das palavras-chave os termos Formação de Professores, Formação docente, Formação Inicial, Formação continuada ou, simplesmente, Formação. 
- Multiletramentos e formação inicial de professores de Língua Portuguesa: um olhar acerca das pesquisas no Brasil

Após a averiguação inicial, descartaram-se todas as publicações que não tratavam de formação inicial de professores de Língua Portuguesa ${ }^{7}$. A partir de então, detectouse que apenas 03 trabalhos se aproximavam dos objetivos de nossa investigação, sendo todos eles dissertações de cursos de Mestrado Acadêmico. O quadro a seguir apresenta os dados dos trabalhos, tendo como base o ano de publicação.

Quadro 2. Pesquisas sobre multiletramentos e tecnologias digitais na formação inicial de professores de Língua Portuguesa

\begin{tabular}{|c|l|l|}
\hline ANO & \multicolumn{1}{|c|}{ TítULO/AUTOR } & \multicolumn{1}{|c|}{ CURSO/IES } \\
\hline \multirow{2}{*}{2015} & $\begin{array}{l}\text { Leitura em Dispositivos Móveis Digitais na Formação } \\
\text { Inicial de Professores (BERNARDO, J. C. O) }\end{array}$ & $\begin{array}{l}\text { Mestrado em Educação } \\
\text { (Universidade Federal do } \\
\text { Triângulo Mineiro - Uberaba) }\end{array}$ \\
\cline { 2 - 4 } & $\begin{array}{l}\text { Gênero Discursivo Filme de Animação Infantil: } \\
\text { Práticas Discursivas e Ação Docente para o o } \\
\text { Multiletramento (DIAS, L. A. X.) }\end{array}$ & $\begin{array}{l}\text { Mestrado em Estudos da } \\
\text { Linguagem (Universidade } \\
\text { Estadual de Londrina) }\end{array}$ \\
\hline \multirow{2}{2018}{} & $\begin{array}{l}\text { Multiletramentos na Formação do(a) Professor(a) } \\
\text { de Língua Portuguesa (LIMA, A. C. A) }\end{array}$ & $\begin{array}{l}\text { Mestrado em Letras (Universidade } \\
\text { Federal de Pernambuco-Recife) }\end{array}$ \\
\hline
\end{tabular}

Fonte: Elaboração própria

Evidentemente, as informações expostas no Quadro 2 são fundamentais não apenas por apresentar algumas investigações já realizadas no Brasil, enfatizando Teses de Doutorado e Dissertações de Mestrado produzidas a partir do tema multiletramentos e tecnologias digitais na formação inicial de professores de Língua Portuguesa, mas, sobretudo, por evidenciar a necessidade de se ampliar os estudos na área no âmbito dos cursos de Mestrado e Doutorado em Letras, bem como de se fortalecer as discussões sobre multiletramentos e uso das tecnologias digitais nos Cursos de Licenciatura em Letras.

Ademais, considerando a relevância de se apresentar um estado da arte, ainda que parcial, a pesquisa que fundamenta este artigo realizou um estudo detalhado dos trabalhos encontrados no Banco de Teses e Dissertações da Capes, destacando os seguintes elementos: objetivos, referencial teórico, metodologia e resultados. O Quadro 3 apresenta um resumo desses dados.

7 A maioria das publicações encontradas apresenta as seguintes especificidades: i) mostra como os professores da educação básica desenvolvem os multiletramentos nas aulas de Língua Portuguesa; ii) aborda os multiletramentos englobando várias disciplinas/áreas do conhecimento; iii) direciona-se para o ensino de outra disciplina ou iv) tem como foco a formação continuada. 
Quadro 3. Descrição das pesquisas investigadas

Trabalho 01 - Leitura em Dispositivos Móveis Digitais na Formação Inicial de Professores (BERNARDO, 2015)

\section{Objetivos}

\section{a) objetivo geral:}

Investigar a viabilidade da leitura em dispositivos móveis digitais na formação inicial de professores.

\section{b) objetivos específicos:}

- verificar as potencialidades dos dispositivos móveis digitais em atividades de ensino e aprendizagem envolvendo processos de leitura;

- relacionar contextos em que os processos de mobile learning e a Pedagogia dos multiletramentos podem contribuir para a formação de leitores críticos;

- identificar no processo de ensino e aprendizagem, via dispositivos móveis digitais, a possibilidade de práticas de ensino proficientes, dinâmicas e interativas.

\section{Referencial teórico}

a) relativo à formação docente: Almeida (2005, 2010), Arroyo (2007), Borges, Aquino e Puentes (2011), Brzezinski (2008), Fanfani (2006), Fernández Cruz (2006), Gabriel (2013), García (1999), Marcelo (2009), Moran (2007), Perrenoud (2000; 2002), Shulman (2005), Tardif e Lessard (2005; 2008) e outros.

b) relativo à legislação federal: Diretrizes Curriculares Nacionais para a Formação de Professores da Educação Básica (2002), Diretrizes Curriculares Nacionais Gerais para a Educação Básica (2010), LDB (1996), PCNEN (2000).

c) relativo aos multiletramentos: New London Group (1996), Cope e Kalantzis (2007, 2009), Kalantzis e Cope (1999), Kress (2010), Kress e Van Leuween (1996, 2001), Rojo $(2012,2013)$ e outros.

\section{Metodologia}

Tipo de Pesquisa: Abordagem Qualitativa, Natureza Aplicada, Viés Explicativo, Pesquisa participante.

Participantes: 21 discentes do primeiro semestre do Curso de Letras da Universidade Federal do Triângulo Mineiro (turma 2014/2), matriculados na disciplina Língua Portuguesa.

Procedimentos:

- Observação participante;

- Registro das informações em diário de campo;

- Aplicação de questionários (um no início das atividades, outro ao final);

- Práticas em sala de aula, intercaladas com as aulas da disciplina de Língua Portuguesa I.

(Foram desenvolvidas 06 práticas, no período de setembro a dezembro de 2014);

- Criação de um canal on-line no Facebook, para comunicação entre os participantes. 
- Multiletramentos e formação inicial de professores de Língua Portuguesa: um olhar acerca das pesquisas no Brasil

\section{Resultados}

Os resultados obtidos nas práticas possibilitaram ratificar situações em que os DMD se mostram oportunos recursos pedagógicos, assim como instrumentos interativos que podem colaborar para efetivação da aprendizagem, pois podem se atuar como suportes de texto práticos e precisos para uma gama de atividades envolvendo processos de leitura. Quanto à leitura em DMD, foi possível perceber que esse suporte textual traz consigo recursos e características que podem facilitar a leitura de muitos tipos e gêneros textuais, sobretudo os ambientados no ciberespaço, considerando-se as particularidades entre leitor e texto e respectivas preferências. Ademais, as práticas realizadas com os estudantes do curso de Letras também apontam caminhos para continuidade da pesquisa, bem como suscitam mais estudos no sentido de aprofundar a análise crítica do papel da aprendizagem por meio de Dispositivos Móveis Digitais.

Trabalho 02 - Gênero Discursivo Filme de Animação Infantil: Práticas Discursivas e Ação Docente para o Multiletramento

(DIAS, 2015)

\section{Objetivos:}

a) objetivo geral: compreender a responsividade dos professorandos, advinda de estudo teórico-metodológico, em contexto de formação inicial, para elaboração didática de um Plano de Trabalho Docente, com textos-enunciado do gênero discursivo filme de animação infantil.

\section{b) objetivos específicos:}

- Investigar se os acadêmicos de Letras da Universidade Estadual do Norte do Paraná UENP campus de Jacarezinho - PR, têm conhecimento da proposta teórico-metodológica que adota gêneros discursivos como eixo de progressão curricular (BRASIL, 1998) ou como orientadora de ensino de Língua Portuguesa (PARANÁ, 2008);

- Explicitar a responsividade demonstrada por professores em formação inicial no decorrer do estudo teórico-prático da perspectiva bakhtiniana dos gêneros discursivos;

- Analisar a mudança na Zona de Desenvolvimento Proximal dos professorandos por meio das manifestações de responsividade durante a elaboração colaborativa do PDT com o gênero filme de animação infantil, mobilizada nos discursos dos professorandos;

- Identificar e descrever as estratégias utilizadas pelos acadêmicos na construção das atividades sequenciadas, que contribuíram para a ampliação dos horizontes discursivos por meio de conceitos de multiletramentos (ROJO, 2008, 2012, 2013), envolvendo o multimodal.

\section{Referencial teórico}

a) relativo à formação docente: Gasparin (2012), Ohuschi (2013), Tardif (2012).

b) relativo à legislação federal: PCN (1998), Orientações Curriculares do Ensino Médio (2006)

c) relativo aos multiletramentos: Daley (2010), Lemke (1998), Rojo (2009, 2012, 2013). 


\section{Metodologia}

Tipo de Pesquisa: Abordagem Qualitativa, Pesquisa Ação de Cunho Etnográfico.

Participantes: o professor pesquisador e 04 discentes do segundo e terceiro ano do Curso de Letras da Universidade Estadual do Norte do Paraná (Campus Jacarezinho) e integrantes do grupo de pesquisa Leitura e Ensino, Estudos Bakhtinianos e o Multiletramento.

\section{Procedimentos:}

- Desenvolvimento de ações: i) estudos para a apropriação das características do gênero; ii) elaboração de Plano de Trabalho Docente para a didatização do gênero filme de animação infantil, no ensino fundamental;

- Registro de informações em diário reflexivo, por todos os participantes;

- Gravações (em áudio) de 26 reuniões do grupo de pesquisa.

Obs.: A pesquisa foi desenvolvida de setembro de 2013 a outubro de 2014.

\section{Resultados}

Os resultados evidenciam alterações positivas nas ZDP dos sujeitos de pesquisa, entretanto, alguns conceitos estudados, como o das técnicas de animação precisam ser ampliados. A produção do PDT mostrou-se complexa, uma vez que muitos conceitos discutidos teoricamente não haviam sido internalizados pelos sujeitos da pesquisa. Porém, com uma reanálise, tais conceitos puderam ser mobilizados e transformados de forma um pouco mais profícua.

Trabalho 03 - Multiletramentos na Formação do(a) Professor(a) de Língua Portuguesa

(LIMA, 2018)

\section{Objetivos}

a) objetivo geral: investigar o nível de letramento digital de docentes em formação continuada e de licenciandos(as) de Letras-Português, da UFPE.

\section{b) objetivos específicos:}

- Perceber se tais sujeitos utilizam/utilizaram o letramento digital como aparato pedagógico de aulas;

- Avaliar se o letramento digital, em aulas de Língua Portuguesa, auxilia/auxiliou a atuação de licenciandos(as) e docentes em formação continuada, com vistas a potencializar ou não a aprendizagem de estudantes da educação básica;

- Analisar a expectativa destes estudantes quanto ao uso de TDIC nas aulas de Língua Portuguesa.

\section{Referencial teórico}

a) relativo à formação docente: Freitas (2010), Moreira (2013), Silva (2012), Silva (2015).

b) relativo à legislação federal: Não constam no trabalho.

c) relativo aos multiletramentos: Kleiman e Sito (2016), Rojo (2012), Rosa (2016), Xavier (2013). 
- Multiletramentos e formação inicial de professores de Língua Portuguesa: um olhar acerca das pesquisas no Brasil

\section{Metodologia}

Tipo de Pesquisa: Método indutivo

Lócus da pesquisa: quatro instituições de ensino básico, sendo duas públicas, situadas em Recife/PE, e duas privadas, localizadas em Jaboatão dos Guararapes/PE, bem como uma instituição de ensino superior, a UFPE (campus Recife), por meio da especificação de uma área do conhecimento, a licenciatura em Letras-Português.

Participantes: um(a) docente de Língua Portuguesa, atuante no Ensino Fundamental II e/ou no Ensino Médio, em cada uma das instituições de ensino básico; discentes de Letras-Português, cursando o sétimo ou oitavo período; estudantes cursando as séries finais do Ensino Fundamental Il e do Ensino Médio.

\section{Procedimentos:}

- Aplicação de três questionários sócio-econômico-tecnológicos com o auxílio da plataforma Google Docs, condizentemente com as características de atuação dos sujeitos investigados, havendo, assim, um questionário para docentes em formação continuada, outro para docentes em formação inicial (licenciandos(as) de Letras-Português da UFPE) e o último para estudantes do ensino básico.

- Distribuição dos dados nas categorias i) respostas /justificativas dos docentes em formação continuada interligadas às respostas/justificativas dos(as) estudantes do ensino básico e ii) respostas/justificativas dos(as) licenciandos(as) concatenadas às "respostas" (informações sobre o curso de Letras-Português) da UFPE.

\section{Resultados}

Os dados revelaram que docentes de Língua Portuguesa e licenciandos(as) de Letras-Português da UFPE são digitalmente letrados(as) e manifestam seus níveis de letramento digital muito mais quando estabelecem relações interpessoais do que profissionais. Numa escala de 1 a 6 (Botelho, 2013), constatou-se que todos os docentes de Língua Portuguesa possuem nível 6 de letramento digital. Três docentes possuem conhecimento elevado sobre percursos de navegação, uso de linguagem on-line, elaboração e publicação de conteúdos em formato de hipertexto etc., mas ainda caminham para estabelecer um domínio desse conhecimento dentro da sala de aula e dar às ações de estudantes com tecnologias digitais mais vieses educacionais. Uma docente consegue manter seu perfil de letramento digital com todas essas características. Os dados também revelaram que 15 licenciandos(as) de Letras-Português da UFPE possuem nível máximo de letramento digital e perfis de navegação na internet que variam entre compreender as funcionalidades de um ambiente digital, com o gerenciamento das próprias ações, e conduzir as ações de outras pessoas.

Fonte: Elaboração própria

Evidentemente, as informações anteriormente expostas contribuem não apenas para uma divulgação de algumas pesquisas já realizadas no Brasil no que diz respeito ao trabalho com multiletramentos e tecnologias digitais na formação inicial de docentes de Língua Portuguesa, como também propiciam importantes reflexões acerca de como os multiletramentos têm sido entendidos/desenvolvidos em alguns cursos de Licenciatura em Letras. Uma análise mais detalhada das pesquisas revela que as propostas realizadas até o momento não coadunam, na maioria das vezes, com os postulados teóricometodológicos da Pedagogia dos Multiletramentos. 
No que concerne ao trabalho 01, as práticas ocorreram intercaladamente com as aulas da disciplina de Língua Portuguesa I $^{8}$. A Figura 1 ilustra a estrutura das práticas desenvolvidas.

Figura 1. Estrutura das práticas de ensino

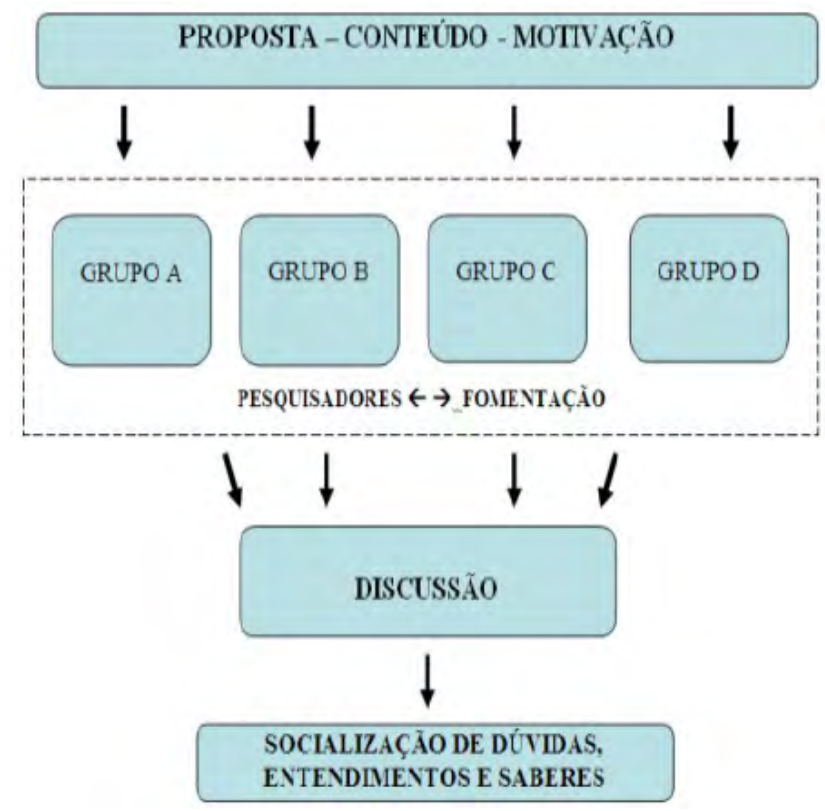

Fonte: Bernardo (2015, p. 91)

De maneira geral, os estudantes eram distribuídos em quatro grupos, com 3 a 6 participantes cada, mas nem sempre os grupos trabalhavam com as mesmas práticas. As atividades iniciavam-se com uma proposta que motivava os grupos, e esses, fomentados pelos pesquisadores, produziam entendimentos a partir das pesquisas em si e de uma discussão entre o grupo. Os momentos de socialização/discussão geral ocorriam posteriormente a todas as práticas, sem exceção, e sempre se realizaram coletivamente. (BERNARDO, 2015).

De maneira geral, as práticas eram voltadas para a discussão de temas/perguntas, tais como: "Por que a leitura em papel é viável?", "Por que a leitura em dispositivos móveis digitais é viável?" (prática 1); comparação de material impresso e digital, como jornais (prática 2); pesquisas sobre temas da atualidade em revistas impressas e Dispositivos Móveis Digitais - DMD (prática 3); levantamento de dados sobre a história da Língua Portuguesa, utilizando livros, gramáticas e DMD (prática 4); levantamento de aplicativos

8 É importante salientar que o pesquisador não era o docente responsável pela referida disciplina e, por isso, algumas aulas foram cedidas ao pesquisador para a realização das atividades. 
- Multiletramentos e formação inicial de professores de Língua Portuguesa: um olhar acerca das pesquisas no Brasil

fomentadores de leitura (prática 5); leitura via rede social (prática 6); socialização de informações da leitura feita por meio DMD (prática 7).

Certamente, o trabalho de Bernardo foi importante por desenvolver nos graduandos uma conscientização acerca da relevância das práticas de leitura no contexto digital. No entanto, não há indícios no texto de que as atividades promoveram discussões teóricometodológicas sobre a Pedagogia dos Multiletramentos. Embora o aporte teórico que norteia a pesquisa seja o da Pedagogia dos Multiletramentos (NLG, 1996), a metodologia utilizada para a realização das práticas não está em consonância com essa teoria. Ademais, pelo que é descrito no trabalho, nota-se que a noção de multimodalidade foi pouco explorada e a ideia da multiculturalidade é relacionada apenas à diversidade de gêneros no contexto digital.

Observa-se também que, como a pesquisa foi realizada com graduandos do primeiro semestre do curso de Licenciatura em Letras, as propostas pedagógicas que envolvem o ensino de Língua Portuguesa na educação básica não foram problematizadas, nem foi possível a construção de sequências didáticas para o ensino da leitura e da escrita no contexto escolar. Nota-se, assim, a necessidade do desenvolvimento de outras ações que possam aprimorar as habilidades dos licenciandos no que concerne ao trabalho com os multiletramentos e as tecnologias digitais no âmbito educacional, em semestres subsequentes do curso.

Diferentemente do trabalho 01, o trabalho 02 foi desenvolvido com graduandos matriculados no segundo e terceiro ano do curso de Letras e, por isso, com mais embasamento teórico-metodológico para a construção de reflexões e proposições para o desenvolvimento dos multiletramentos no contexto escolar. Além disso, o pesquisador também era professor na instituição de ensino superior e integrante do mesmo grupo de pesquisa no qual a investigação foi realizada.

No entanto, do mesmo modo que na pesquisa anterior, a proposta metodológica que fundamentou o trabalho 02 não foi o da Pedagogia dos Multiletramentos. Aliás, o referencial teórico utilizado na Dissertação para tratar de multiletramentos englobou apenas os postulados de Daley (2010), Lemke (1998) e Rojo (2009, 2012, 2013). O Grupo de Nova Londres é apenas mencionado a partir de uma citação de Rojo (2011). Ademais, verifica-se que os multiletramentos não aparecem como tema principal de discussão nas reuniões do grupo de pesquisa (cf. informações expostas na página 103 da Dissertação).

Sendo assim, nota-se que, no decorrer das atividades propostas para os participantes do grupo de pesquisa, não foram discutidos textos teóricos que tratassem de multiletramentos, multimodalidade e/ou multiculturalidade (cf. Seção 4.6 da Dissertação). 
Os textos centraram-se nos estudos: i) dos gêneros do discurso, na perspectiva Bakhtiniana; ii) da animação digital; iii) da metodologia do Plano de trabalho Docente, conforme a pedagogia histórico-crítica. A abordagem dos temas multiletramento e multimodalidade se deu apenas nas discussões sobre a caracterização do gênero filme de animação infantil, mas o assunto parece ter sido pouco discutido, e os pressupostos da Pedagogia dos Multiletramentos não foram analisados. A proposta metodológica que fundamentou a prática e o Plano de Trabalho Docente (PDT) construído pelos discentes foi a Pedagogia histórico-crítica. Nessa perspectiva, a proposta envolveu as seguintes etapas.

Quadro 4. Plano de trabalho docente

\begin{tabular}{|c|c|c|c|c|}
\hline $\begin{array}{c}\text { PRÁTICA } \\
\text { Zona de } \\
\text { desenvolvimento } \\
\text { real }\end{array}$ & \multicolumn{3}{|c|}{$\begin{array}{l}\text { TEORIA } \\
\text { Zona de desenvolvimento proximal }\end{array}$} & $\begin{array}{c}\text { PRÁTICA } \\
\text { Zona de } \\
\text { desenvolvimento } \\
\text { atual que se torna } \\
\text { real }\end{array}$ \\
\hline $\begin{array}{l}\text { Prática social } \\
\text { inicial do } \\
\text { conteúdo }\end{array}$ & Problematização & Instrumentalização & Catarse & $\begin{array}{l}\text { Prática social final } \\
\text { do conteúdo }\end{array}$ \\
\hline
\end{tabular}

Fonte: Dias (2015, p. 91)

Nota-se que a construção do PDT não envolveu, portanto, os postulados teóricos dos multiletramentos, embasados no conceito de Design. Ademais, pelo que é descrito no trabalho, as noções de multimodalidade e multimodalidade foram pouco valorizadas. No PTD construído pelos discentes, com base no filme Shrek2, a multimodalidade é explorada na etapa II-problematização (dimensão estética) e na etapa III-instrumentalização, apenas no que concerne ao uso das cores. Também na fase da instrumentalização, a música é incluída no plano de trabalho somente com o objetivo de explorar o conteúdo temático. Os aspectos sonoros não são enfatizados. Já no que concerne à multiculturalidade, é abordada, indiretamente, apenas por meio de uma das perguntas propostas na etapa da catarse: "Relembrar filmes que acontecem o preconceito, quais? Onde isso acontece?" (DIAS, 2015, p. 130).

Como resultado das atividades propostas, alguns alunos construíram conceitos equivocados acerca dos multiletramentos, demonstrando que ainda não estão preparados para lidar com as práticas multimodais e multiculturais de leitura e escrita no contexto escolar. Os depoimentos a seguir, produzidos pelos participantes identificados como PA e PD, comprovam esses dados. 
- Multiletramentos e formação inicial de professores de Língua Portuguesa: um olhar acerca das pesquisas no Brasil

Quadro 5. Conceitos de multiletramentos construídos por PA e PD

É saber reconhecer e utilizar os diversos gêneros discursivos existentes nas esferas de atividades da comunicação humana. Assim, é possível construir pessoas capazes de ler crítica e ativamente os inúmeros enunciados que circulam diariamente em seu meio social. (Diário de PA em 02/10/2014)

Multiletramento é ser letrado para diversos meios, situações, possuir conhecimentos, um dos exemplos mais citados quando se fala em multiletramento é o letramento digital que hoje tem sido de grande importância, inclusive no contexto escolar. Quando uma pessoa é letrada digitalmente isso quer dizer que possui habilidades para realizar operações em programas, softwares que auxiliam no desenvolvimento de trabalhos escolares, de atividades no trabalho, ou seja, facilitam sua vida por meio desse conhecimento ou letramento digital. (Diário de PD em 02/10/2014)

Fonte: Dias (2015, p. 176)

O próprio autor reconhece: "PD confunde o termo multiletramento com letramento digital, porém sua ZDP encontra-se em transformação" (DIAS, 2015, p. 176). A confusão entre os termos também pode ser constatada no trabalho 3, pois, embora a dissertação tenha sido intitulada "Multiletramentos na Formação do(a) Professor(a) de Língua Portuguesa", a investigação não tem como foco os multiletramentos, mas os letramentos digitais. Isso pode ser observado ao se analisar os objetivos da pesquisa, bem como a metodologia desenvolvida e os resultados do estudo (conforme Quadro 3). O trabalho visa, de maneira geral, investigar o nível de letramento digital de docentes em formação continuada e de licenciandos(as) de Letras-Português, da UFPE. Sendo assim, não apresenta uma base teórica consistente relacionada à Pedagogia dos Multiletramentos. E a construção de dados ocorre apenas mediante a aplicação de um questionário com docentes de Língua Portuguesa, graduandos do curso de Letras e discentes da educação básica. Não é desenvolvida uma proposta de trabalho voltada para os multiletramentos, seja no ensino superior ou na educação básica.

Visto isso, depreende-se que muito se discute sobre a importância do uso das tecnologias digitais na educação básica. No entanto, as pesquisas aqui focalizadas sugerem que os cursos de Licenciatura em Letras ainda apresentam lacunas na formação dos profissionais no que diz respeito ao trabalho com as práticas multimodais e multiculturais de leitura e escrita intermediadas pelo uso de tais tecnologias, corroborando os dados apresentados por Gatti (2010) e Lima e Loureiro (2016). E mais: o mapeamento das pesquisas presentes no Banco de Teses e Dissertações on-line da Capes indica ainda haver poucos estudos sobre os multiletramentos e o uso das tecnologias digitais no processo inicial de formação de professores de Língua Portuguesa no Brasil. É crucial, portanto, a ampliação das discussões e investigações nesse âmbito, tendo em vista a importância da temática nos processos de ensino e aprendizagem da Língua Portuguesa. 


\section{Conclusão}

O presente trabalho foi elaborado no intuito de analisar pesquisas que discutem como os multiletramentos têm sido entendidos/promovidos nos cursos iniciais de formação de professores de Língua Portuguesa, em alguns contextos no Brasil. Para tanto, realizou-se um mapeamento das pesquisas presentes no Banco de Teses e Dissertações on-line da Capes, no período de 2015 a 2019. Os resultados da pesquisa evidenciaram a escassez dos estudos na área, uma vez que apenas 03 (três) dissertações de mestrado abordaram o tema Multiletramentos, Tecnologias Digitais e Formação Inicial de Professores de Língua Portuguesa, no período selecionado.

Constatou-se também que, de maneira geral, os trabalhos descritos nessas dissertações não desenvolvem propostas didático-metodológicas embasadas na Pedagogia dos Multiletramentos. Por um lado, nota-se que os aspectos que envolvem a multimodalidade dos textos ainda são pouco enfatizados. Por outro, verifica-se que os elementos multiculturais que constituem as sociedades pós-modernas (considerando tanto a diversidade corporal, espacial, temporal e institucional, quanto as diferenças sexuais, raciais, de gênero e outras) não são abordados nos trabalhos. A diversidade é entendida, em alguns momentos, como a variedade de gêneros presentes no contexto digital.

Nota-se, assim, que parece ainda haver um longo caminho a ser percorrido, a fim de que os multiletramentos sejam desenvolvidos no ensino superior com vistas a contribuir para a ampliação das práticas de leitura e escrita na educação básica e, consequentemente, para o ensino de Língua Portuguesa no contexto educacional.

Por isso, as reflexões propostas neste artigo reiteram alguns aspectos relevantes em relação ao processo de formação inicial dos professores de Língua Portuguesa: além de valorizar uma aprendizagem pautada no uso das tecnologias digitais, o que não significa dizer que toda prática de leitura e escrita no contexto digital é multiletramento (é preciso se distinguir multiletramentos de letramentos digitais, por exemplo), o processo de formação docente precisa mobilizar conhecimentos que contribuam para a profissionalização dos graduandos, sobretudo, ao: i) estimular a interação entre diferentes sujeitos, espaços e saberes no processo de construção do conhecimento; ii) possibilitar uma aprendizagem pautada em ações didáticas que valorizem textos multimodais e multiculturais, vinculados ao mundo contemporâneo e às atuais necessidades dos estudantes da educação básica e iii) propiciar mudanças de atitude do futuro professor em direção à inovação educativa, por meio da compreensão prática de fenômenos teórico-metodológicos que envolvam as diferentes tecnologias e os multiletramentos. 
- Multiletramentos e formação inicial de professores de Língua Portuguesa: um olhar acerca das pesquisas no Brasil

Portanto, espera-se que este trabalho possa ampliar as discussões no campo da Linguística Aplicada e, ao mesmo tempo, contribuir com pesquisadores e professores que atuam no ensino superior, com reflexões sobre os multiletramentos e uso das tecnologias digitais no processo inicial de formação de docentes na área de Letras.

\section{Referências}

BERNARDO, J. C. O. Leitura em dispositivos móveis digitais na formação inicial de professores. 2015. Dissertação (Mestrado em Educação) - Universidade Federal do Triângulo Mineiro, Uberaba, 2015.

BRASIL. Decreto n 3.276, de 06 de dezembro de 1999. Dispõe sobre a formação em nível superior de professores para atuar na educação básica, e dá outras providências, 1999. Disponível em https://presrepublica.jusbrasil.com.br/legislacao/110851/ decreto-3276-99. Acesso em: 05 jan. 2021.

BRASIL. Resolução CNE/CP no 1, de 18 de fevereiro de 2002. Institui Diretrizes Curriculares Nacionais para a Formação de Professores da Educação Básica, em nível Superior, Curso de Licenciatura, de graduação Plena, 2002. Disponível em: http:/ portal. mec.gov.br/pnaes/323-secretarias-112877938/orgaos-vinculados-82187207/12861formacao-superior-para-a-docencia-na-educacao-basica. Acesso em: 05 jan. 2021.

BRASIL. Ministério da Educação. Diretrizes Curriculares Nacionais Gerais da Educação Básica. Brasília, DF, MEC/SEB, 2013. Disponível em: http://portal.mec.gov.br/docman/ julho-2013-pdf/13677-diretrizes-educacao-basica-2013-pdf/file. Acesso em: 05 jan. 2021.

BRASIL. Resolução CNE/CP n. 02/2015, de $1^{\circ}$ de julho de 2015. Define as Diretrizes Curriculares Nacionais para a formação inicial em nível superior (cursos de licenciatura, cursos de formação pedagógica para graduados e cursos de segunda licenciatura) e para a formação continuada, 2015. Disponível em: http://portal.mec.gov.br/pnaes/323secretarias-112877938/orgaos-vinculados-82187207/12861-formacao-superior-para-adocencia-na-educacao-basica. Acesso em: 05 jan. 2021.

COPE, B.; KALANTZIS, M. (org.). Multiliteracies. Literacy learning and the design of social futures. Londres: Routledge, 2000.

DALEY, E. Expandindo o conceito de letramento. Trabalhos em Linguística Aplicada, Campinas, v. 49, n. 2, p. 481-491, jul./dez. 2010. 
DIAS, L. A. X. Gênero discursivo filme de animação infantil: práticas discursivas e ação docente para o multiletramento. 2015. Dissertação (Mestrado em Estudos da Linguagem) Centro de Letras e Ciências Humanas, Universidade Estadual de Londrina, Londrina, 2015.

GATTI, B. A. Formação de Professores no Brasil: características e problemas. Educação \& Sociedade, Campinas, v. 31, n. 113, p. 1355-1379, out./dez. 2010.

HALL, S. A identidade cultural na pós-modernidade. 7. ed. Rio de Janeiro: DP\&A, 2002.

KUMARAVADIVELU, B. A linguística aplicada na era da globalização. In: MOITA LOPES, L. P. (org.). Por uma lingüística aplicada indisciplinar. 2. ed. São Paulo: Parábola Editorial, 2006. p. 129-148.

LIMA, L.; LOUREIRO, R. C. Relação entre Tecnologias Digitais e Docência: a Compreensão de Licenciandos sobre Tecnodocência. Informática na Educação: Teoria \& Prática, Porto Alegre, v. 19, n. 3, p. 145-160, set./dez. 2016.

LEFFA, V. J. A linguística aplicada e seu compromisso com a sociedade. Trabalho apresentado no VI Congresso Brasileiro de Linguística Aplicada. Belo Horizonte: UFMG, 7-11 de outubro de 2001. Disponível em: http://www.leffa.pro.br/textos/trabalhos/ la_sociedade.pdf. Acesso em: 05 jan. 2021.

LEMKE, J. L. Multiplying Meaning: visual and verbal semiotics in scientific text. In: MARTIN, J. R.; VEEL, R. (ed.). Reading Science. London: Routledge, 1998. p. 87-113.

LIMA, A. C. A. Multiletramentos na formação do(a) professor(a) de língua portuguesa. 2018. Dissertação (Mestrado em Letras) - Universidade Federal de Pernambuco, Recife, 2018.

MOITA LOPES, L. P. Lingüística aplicada e vida contemporânea - problematização dos construtos que têm orientado a pesquisa. In: MOITA LOPES, L. P. (org.). Por uma lingüística aplicada indisciplinar. 2. ed. São Paulo: Parábola Editorial, 2006. p. 85-108.

PENNYCOOK, A. Uma lingüística aplicada transgressiva. In: MOITA LOPES, L. P. (org.). Por uma lingüística aplicada indisciplinar. 2. ed. São Paulo: Parábola Editorial, 2006. p. 67-84. ROJO, R. (org.). Escola conect@da: os multiletramentos e as TICs. São Paulo: Parábola, 2013. 
- Multiletramentos e formação inicial de professores de Língua Portuguesa: um olhar acerca das pesquisas no Brasil

ROJO, R. Pedagogia dos multiletramentos: diversidade cultural e de linguagem na escola. In: ROJO, R.; MOURA, E. (org.). Multiletramentos na escola. São Paulo: Parábola Editorial, 2012. p. 11-32.

ROJO, R. Letramentos múltiplos, escola e inclusão social. São Paulo: Parábola Editorial, 2009.

SILVA, L. R. Análise de Discurso Crítica, Letramento e Gênero Social. Signótica Especial, v. 2, p. 75-88, 2006. Disponível em: https://doi.org/10.5216/sig.v0i0.3637. Acesso em: 05 jan. 2021.

STREET, B. V. (ed.). Cross-cultural approaches to literacy. Cambridge: Cambridge University Press, 1993.

THE NEW LONDON GROUP. A pedagogy of multiliteracies: Designing social futures. Harvard Educational Review, v. 66, n. 1, p. 60-92, 1996.

COMO CITAR ESTE ARTIGO: SANTOS, Fernanda Maria Almeida dos. Multiletramentos e formação inicial de professores de Língua Portuguesa: um olhar acerca das pesquisas no Brasil. Revista do GEL, v. 18, n. 2, p. 160-185, 2021. Disponível em: https://revistadogel.gel.org.br/

Submetido em: 08/06/2021 | Aceito em: 01/06/2021. 